\title{
The Role of eLearning in Enterprise Training in Australia
}

\author{
Chau Giang \\ University of Central Queensland, Australia
}

\begin{abstract}
eLearning is one of the essential components of workplace training in recent implementations of enterprise systems at large Australian organisations. Often used in a blended learning approach, eLearning plays a major role in providing basic information to a large number of users in typically short system roll-out period of Just-In-Time (JIT) training projects. The effectiveness of eLearning, however, can be only fully realized by designing appropriate instructional materials that employ relevant business scenarios and sufficient user interactivity, coupled with the provision of post-training support, in order to provide good learning experience and ensuring the efficient use of the rolled-out systems.
\end{abstract}

Keywords: eLearning, Enterprise Systems, EDRMS Implementation, JIT Training, Blended Learning, Knowledge Management.

\section{Introduction}

Australia is the fifth largest ICT market in the Asia-Pacific region with a total forecasted ICT spending of US $\$ 1,457$ billion in 2013 . With a $4.3 \%$ share of this market, Australia offers a unique environment for global ICT solution development in the areas of telecoms, financial services, digital content and eHealth (Austrade, 2011).

In the eHealth and eLearning areas, ICT investment opportunities amount to US $\$ 28$ billion, almost half of the current spending budget. These investment opportunities are forecasted to growth at $8 \%$ Compound Annual Growth Rate (CAGR) with the government expansionary spending in cloud-based infrastructure and a whole-of-government approach in ICT procurement policy; and commitment to improve operations, increase productivity and efficiency across state, local and federal verticals (ARN, 2012).

Introduced in 2011, the Digital Transition Policy requires all Australian government departments and agencies to move to digital recordkeeping and manage all government information in digital formats. By 2015, the current recordkeeping practices of print-to-paper hardcopy files will be completely replaced with digital records that are to be created, stored and securely managed for efficiency, accountability, legal compliance and risk reduction purposes (NAA, 2013).

It is during this time that the author has had the opportunities to be involved in a number of large implementations of enterprise record management systems including the electronic research administration system, the electronic medical record system and the electronic document record management (EDRMS) system at research institutions, state and federal organisations. Of particular relevance is the author's active engagement in using latest ICT technologies in the design, development and creation of enterprise training programs that include eLearning for delivery to thousands of users in a wide range including administrative staff, 
academic researchers, analysts, nurses, allied health professionals, doctors, lawyers and government officials.

\section{Enterprise Record Management System Implementations}

In aligning with the Digital Transition policy and in order to achieve the government's goal of creating a new digital recordkeeping system, there had been a large number of EDRMS implementation activities in the Australian public sector at the local, state and federal levels over the past few years (Nguyen and Swatman, 2009).

Recent EDRMS implementation projects at large government organisations would typically involve the use of external consultants to provide knowledge and expertise in technology, implementation, change management and user training. The enterprise training programs would typically be Just-in-Time (JIT) training and provided at system go-live or rollout over a short period of two to three weeks per business unit. Most often system training would employ the use of a blended approach in which elements of online and face-to-face are combined to deliver flexible learning options to learners to cater for different learning styles and accessibility in a distributed organisation.

\section{The Role of eLearning in Australi- an Workplace Training}

Often referred to as online training, eLearning involves the use of electronic technologies such as web-based courses, multimedia, interactive flash and webinars to provide a flexible learning environment that is accessible to a wide range and large scale of learners. eLearning can also be used as an effective knowledge management platform to capture, transfer and share knowledge within an organisation.
eLearning promotes a self-paced and personalised learning that is more suitable to the current workforce than the traditional face-to-face training method. This method has been used extensively as a valuable and cost-effective training and skills development solution to many organisations (FLAG, 2011).

Over the past ten years, the Australian government has allocated hundreds of million dollars to facilitate and encourage the use of eLearning for more flexible and effective training in the Vocational Education and Training (VET) sector. And in order to achieve national training objectives, to increasing participation in training and work and improving the skill levels of the Australian workforce, the Australian government has put together a three-year program, the National VET eLearning Strategy, to promote broadband-enabled training using the new technological environment of National Broadband Network (DIICCSRTE, 2012).

In a study conducted by Callan (2009) on the use of eLearning in organisations, it has been found that eLearning can be used as a responsive, flexible and effective approach to training for the delivery of foundation knowledge and theory in trade qualifications, and to address national skills shortages. The major benefits of eLearning that businesses can realized are greater flexibility, increased levels of on-the-job training, better quality of training across multiple locations, customization to suit business needs and cost savings.

Presently eLearning is used as an essential component in large enterprise training programs, complementing the face-to-face instructor-lead training method. Majority of these eLearning systems, however, are one-module-fits-all and are often created by external consultants that might not necessarily have the business and internal process knowledge of the organisation. These eLearning sys- 
tems would normally contain only basic information about the new system and the mechanics of system navigation. There is notably lack of interactive features and simulation of real-life working environment for hands on practice and adequate learning of new system complexity.

\section{Critical Success Factors and Impact of eLearning on Enterprise Train- ing}

Case studies on Australian government agencies' successful EDRMS implementations and best practice sites have indicated that training and executive support were the most critical success factors in gaining user acceptance and adoption of the newly rolled out system (NAA, 2011).

eLearning has been recognized by Bowman and Kearns (2009) as an effective tool that can be used creatively to develop employability skills, as per the requirements set out by the Australian VET competency standards in training packages of learning, self management, planning and organising, problem solving, communication, team work, initiative and enterprise and use of technology.

Baldwin-Evans' findings (2004) in a survey across a range of organisations, in over 14 countries across Europe, Middle East and Africa, are that in the current economic climate, it is almost impossible for organisations to train a diverse and geographically dispersed employee base without the availability and effectiveness of eLearning, and the lack of effective ongoing training will reduce organisations' competency and efficiency and might put their competitiveness at risk.

The global trend of eLearning adoption has the potential in delivering greater learning experience in collaborative learning and social interaction from eLearning in workplace environment (Daneshgar and Van Toorn, 2009).
While some change management proponents would prescribe pure measures of behavioral change at both individual and organisation levels for an enterprise system implementation to be successful, others would call for more considerations on the affective, social and contextual aspects of eLearning to avoid the "narrow, industrialized "production" of workplace knowledge" (Servage, 2005).

From the author's long-term practical training experience, it is the combination of appropriate eLearning materials, customized training and availability of posttraining support that would ensure a successful completion of user's learning process. Thereby increases user's confidence and improves the effective use of the newly implemented system, both of which have proved to be critical factors in system acceptance and adoption in many organisations (NAA, 2011).

The effectiveness of the eLearning materials can be achieved by designing appropriate instructional materials that employ relevant business scenarios and sufficient user interactivity to provide not only basic information but more realistic learning and practice of new system concepts and knowledge. With the availability of latest technology and development tools, interactive eLearning can be successfully designed, authored and delivered to multiple devices. A competent trainer would understand the capability and learning needs of users in order to provide appropriate customised training to suit learners' needs. The availability of post-training support, shortly after training, is critical for users to be able to confidently and successfully apply the newly learned concepts in a real-life working environment. This applied learning approach is important in providing good user learning experience, building user confidence and improving the effective use of the implemented enterprise system. 


\section{Conclusion}

Recognizing the importance of valuing adult learners in a corporate environment (Waight and Steward, 2005), it can be asserted that eLearning can be effective utilized in training at both individual and organizational levels in terms of engagement, learning and transfer of knowledge.

eLearning should be employed as a critical component in enterprise training programs, with interactive scenario-based instructional materials, coupled with customised face-to-face training and posttraining support, to provide good user learning experience and to ensure that knowledge is successfully transferred and efficiently applied for maximum acceptance and adoption of the newly implemented enterprise system.

\section{References}

[1] Austrade, "Australia - A Wealth of Opportunities", Benchmark Report 2011.

[2] ARN, "ICT government spending remains cautious", 2012. Available from http://www.arnnet.com.au/article/444 995/ict_government_spending_remai ns_cautious/.

[3] National Archive of Australia (NAA), "Digital Transition Policy", 2013. Available from http://www.naa.gov.au/recordsmanagement/digital-transitionpolicy/index.aspx

[4] L. Nguyen, and P. Swatman, "EDRMS Implementations in the Australian Public Sector", $20^{\text {th }}$ Australasian Conference on Information Systems, Melbourne, pp. 915-928, 2009.

[5] Flexible Learning Advisory Group (FLAG), "Enabling workforce development: Insights from industries using e-learning”, 2011.
[6] Australian Government Department of Industry, Innovation, Climate Change, Science, Research and Tertiary Education(DIICCSRTE), "National VET E-learning Strategy 20122015", 2012.

[7] V. Callan, "How organizations are using e-learning to support national training initiatives" - Final Report, Australian Department of Education, Employment and Workplace Relations (DEEWR), 2009.

[8] National Archive of Australia, "Implementing an EDRMS: Lessons from Agencies", 2011a.

[9] National Archive of Australia, "Implementing an EDRMS: Department of Parliamentary Services Case Study", 2011 b.

[10] National Archive of Australia, "Implementing an EDRMS: Geoscience Australia Case Study", 2011c.

[11] K. Bowman, and P. Kearns, "The Impact of E-learning on Employability Skills Development" - Final Report, DEEWR, 2009.

[12] K. Balwin-Evans, "Employees and elearning: what do the end-users think?", Industrial and Commercial Training, vol. 36, no. 7, pp. 269-274, 2004.

[13]F. Daneshgar, and C. van Toorn, "eLearning in the Workplace versus eLearning in Higher Education", Australian Council for Computers in Education, vol. 24, no. 1, pp. 16-22, 2009.

[14] L. Servage, "Strategizing for workplace e-learning: some critical considerations", Journal of Workplace Learning, vol. 17, no. 5/6, pp. 304317, 2005.

[15] C. Waight, and B. Stewart, "Valuing the adult learner in e-learning: part two - insights from four companies", Journal of Workplace Learning, vol. 17, no. 5/6, pp. 398-414, 2005. 